\title{
Surgical Outcome Of Spontaneous Intracerebral Haematoma Through Keyhole Craniectomy
}

\author{
M Hossain ${ }^{1}$, SU Ahmed ${ }^{2}$, SAA Ansary ${ }^{3}$, SMK Islam ${ }^{4}$
}

\begin{abstract}
Management of spontaneous intracerebral haematoma (SICH) is divided into two groups - medical and surgical interventions. Although surgical management is controversial, it can be life saving when patient is deteriorating. Surgical techniques varies from large craniotomy, burr hole aspiration, stereotactic \& endoscopic evacuation of haematoma. Forty eight patient of SICH were treated surgically using keyhole craniectomy technique, small craniectomy of 2-2.5 cm diameter. Surgical outcome assessed by Glasgow Outcome Score (GOS). Post-operative CT scan was done in all cases. Good recovery was achieved in 2 cases (4\%), moderate disability in 20 cases (42\%), 5 patients remain in vegetative state. Good evacuation of haematoma was seen in 42 patients except 6 cases deteriorated by post-operative CT scan. Surgical evacuation of SICH through keyhole technique is minimally invasive, safe and can achieve desired result. Patient with a GCS $>9$ prior to surgery demonstrate a better outcome with this minimally invasive method.
\end{abstract}

\section{Introduction}

Spontaneous intracerebral haemorrhage accounts for 10 $-30 \%$ of all stroke patients. It is associated with high morbidity and a 6-month mortality of $30-50 \%$. Primary SICH originates from the spontaneous rupture of the small vessels and arterioles damaged by chronic hypertension or amyloid angiopathy. Role of surgical management is controversial ${ }^{1}$. Current practice favours surgical interventions in following situations - lobar haemorrhage, clot volume between 20 to 80 deteriorating neurological status, relatively young patients and haemorrhage causing midline shift or raised intracranial pressure. In cerebellar haematoma above $3 \mathrm{~cm}$ diameter causing hydrocephalus generally requires surgery ${ }^{2-4}$. Surgical techniques vary from large craniotomy, burr hole aspiration, stereotactic \& endoscopic evacuation of haematoma, stereotactic fibrinolytic therapy etc ${ }^{5-9}$.

1. Dr. Mohammad Hossain, MS (Neurosurgery), Assistant Professor, Dept. of Neurosurgery, BSMMU, Dhaka.

2. Dr. Shafique Uddin Ahmed, Ph.D (Neurosurgery), Ex Professor \& Head, Dept. of Neurosurgery, DMC, Dhaka.

3. Dr. Shamse Ara Akterjahan Ansary, MBBS, EMO, DMCH, Dhaka.

4. Dr. S. M. Khabirul Islam, MCPS (Forensic Medicine), Assistant Professor, Dept. of Forensic Medicine, FMC, Faridpur.

Address of correspondence:

Dr. Mohammad Hossain, MS (Neurosurgery),

Assistant Professor, Dept. of Neurosurgery, BSMMU, Dhaka.

Phone: +88-01819231842. E-mail: mhossain_ns@yahoo.com.
We had operated using keyhole craniectomy technique, small craniectomy of 2-2.5 cm diameter. The ideal goal of surgical treatment of SICH is to remove as small clot as possible with the least amount of brain trauma from the surgery itself.

\section{Materials \& Methods}

This was a retrospective study of 48 cases of SICH treated surgically through keyhole craniectomy (2-2.5 $\mathrm{cm}$ diameter) in neurosurgery department of Dhaka Medical College Hospital from February 2000 to January 2005. Clinical details which were recorded including age of the patient, GCS prior to surgery and location of haematoma. Volume of haematoma was calculated using Peterson and Epperson equation ${ }^{10}$. Surgical outcome were assessed by Glasgow Outcome Scale. Post operative CT scan was done in all cases within $48-72$ hours after surgery. Surgical outcome were recorded in $1^{\text {st }}$ week, 1 month, 3 months and 6 months intervals.

Surgery was performed under general anaesthesia. A vertical incision was made. The burr hole widened into craniectomy measuring $2-2.5 \mathrm{~cm}$ in diameter, over relatively silent area of the cortex and near to the haematoma as possible. 


\section{Results}

Out of 48 patients, 32 were males and 16 were females. Age varies from $3^{\text {rd }}$ to $8^{\text {th }}$ decade. Most of the haematomas were in basal ganglionic region: 34 patients (71\%) involving putamen \& globas pallidus and 14 patients (29\%) had lobar haematoma. Two patients had intraventricular extension.

Hypertension 32 (66\%) and diabetes mellitus 12 (26\%) were the common associated conditions. 25 patients (52\%) were in Glasgow Coma Scale (GCS) 6-8, 9 patients $(18.5 \%)$ were between GCS $9-12$ and 6 patients $(12.5 \%)$ were in GCS $13-15$ and 8 patients $(16.5 \%)$ were in GCS $<6$ preoperatively. The volume of the haematoma varied from $30 \mathrm{ml}$ to $75 \mathrm{ml}$.

The surgical outcome was assessed according to Glasgow Outcome Scale (GOS). They were:

$5=$ Good recovery, mild to nil disability ( 2 patients, $4 \%$ ) $4=$ Moderate disability, disabled but independent $(20$ patients, $42 \%$ )

$3=$ Severe disability, conscious but disabled and dependant (6 patients, $12.5 \%$ )

$2=$ Persistent vegetative state (5 patients, $10.5 \%)$

$1=$ Death $(15$ patients, $31 \%)$

Surgical outcome was better in younger age group than patients with advanced age. Outcome according to GCS prior to surgery: good recovery in 2 patients (GCS 13 $15)$, moderate disability in 4 patients with GCS 13-15 $(100 \%), 6$ patients with GCS 9-12 and 10 patients with GCS $6-8$. All patients with GCS less than 6 had a poor out come.

All the patients underwent repeat CT scan post operatively 48 to 72 hours after operation. Subtotal and near total evacuation of haematoma was seen in 42 patients.

Table I: Post operative outcome of different groups as per GOS (Glasgow Outcome Score) scale 1 month after surgery

\begin{tabular}{lcccccc}
\hline $\begin{array}{l}\text { Group of } \\
\text { patients }\end{array}$ & $\begin{array}{l}\text { No. of pt. } \\
\text { operated }\end{array}$ & $\begin{array}{l}\text { Good } \\
\text { recovery }\end{array}$ & $\begin{array}{l}\text { Moderate } \\
\text { disability }\end{array}$ & $\begin{array}{l}\text { Severe } \\
\text { disability }\end{array}$ & $\begin{array}{l}\text { Persistent } \\
\text { vegetative } \\
\text { state }\end{array}$ & Death \\
I & 8 & - & - & - & 1 & 7 \\
$($ GCS $<6)$ & & & & & & 7 \\
II \\
(GCS 6-8) & 25 & - & 10 & 4 & 4 & 7 \\
III & & & & & & 1 \\
(GCS 9-12) & 9 & - & 6 & 2 & - & 1 \\
IV \\
GCS 13-15) & 6 & 2 & 4 & - & - & - \\
\hline Total & 48 & 2 & 20 & 6 & 5 & 15 \\
\hline
\end{tabular}

\section{Discussion}

Intracerebral haematoma secondary to hypertension are found in basal ganglia, putamen \& globus pallidus, thalamus, cerebral lobes, cerebellum and brain stem ${ }^{1,5}$. Various surgical techniques of $\mathrm{SICH}$ have been mentioned. Tsementzis has advocated a method of small trephine craniotomy $3 \mathrm{~cm}$ in diameter and evacuation of the haematoma through this craniotomy ${ }^{5}$.

We adopted this experience with keyhole craniectomy in this evacuation process of spontaneous intracerebral haematomas. Keyhole craniectomy is a minimally invasive technique by which total or near total evacuation of the haematoma can be done with excellent haemostasis. Keyhole craniectomy is less invasive method requiring less operating time and less blood loss. Associated morbidities of craniectomy such as prolonged operative time $\&$ more blood loss can be avoided by the keyhole technique.

The 'edge effect' resulting in compression of the brain and the cortical veins along the edges of craniectomy is one of the disadvantages of this procedure. But endoscope is usable through this approach. Keyhole craniectomy can be extended into formal craniectomy if secondary lesions such as arteriovenous malformation or tumour are encountered.

The surgical procedure can be performed at all neurosurgical centers with basic neurosurgical infrastructure, without any expensive instruments. Patients with lobar haematoma had a better outcome when compared to the basal ganglionic haematoma with ventricular extension almost $100 \%$ mortality.

The preoperative GCS is directly related to the surgical outcome. Patients with a GCS less than 6 had bad prognosis while those between13-15 had good outcome. When volume of haematoma more than $60 \mathrm{ml}$ had bad prognosis. Early surgery predicted better result.

\section{Conclusion}

Surgical evacuation of SICH through keyhole craniectomy technique is minimally invasive, safe and achieve desired result. Patients with a GCS $>13$ prior to surgery demonstrate better outcome with this minimally invasive technique. 


\section{References}

1. Wood and Broderick JP. Spontaneous intracerebral haemorrhage: Epidemiological and clinical presentation. Neurosurg clin N Am. 2002;13:265-279.

2. Siddique MS, Mendelow AD. Surgical treatment of intracerebral haemorrhage. Br Med Bull. 2000;56(2):444-56.

3. Escosa bage M, Sola RG. Surgical indications in non-traumatic intracerebral haemorrhage Rev. Neurol. 2001;32(11):1060-2.

4. Lejeune JP, Thines L. Neurosurgical management of spontaneous cerebral hemorrhage. J Neuroradiol. 2003;30(5):332-5.

5. Tsementzis SA. Surgical management of intracerebral hematomas. Neurosurgery 1985;16(4):562-72.

6. Zucarello M, Andaulz N, Wanger KR. Mimimally invasive therapy for intracerebral hematomas. Neurosurg Clin N Am. 2002;13(3):349-54.

7. Peresdov VV. Strategy, technology and techniques of surgical treatment of supratentorial intracerebral hematomas. Comput Aided Surg. 1999;4(1):51-63.

8. Teernstra OPM, Ever SMAA, Lodder J, Leffers P, Franke CL Blaauw G. Stereotactic treatment intracerebral haematoma by means of a plasminogen activator. A multicenter randomized controlled trial (SICHPA). Stroke 2003;34(4):968-74.

9. Myung-Hyun K, Jun-Hyeok S, Sung-Hak K, Dong-Bin P, Kyuman S. A new trend in operative technique for intracerebral hemorrhage: a comparative study of stereotactic endoscopic removal and stereotactic catheter drainage. Journal of Korean Medical Science 1998;13(5):533-40.

10. Peterson OF, Esperson JO. Extradural hematomas; measurement of size by volume summation of CT Scanning. Neuroradiology $1984 ; 26: 363-7$ 